\title{
Mortes súbitas em bovinos causadas por Amorimia exotropica (Malpighiaceae) no Rio Grande do Sul ${ }^{1}$
}

\author{
Saulo P. Pavarini ${ }^{2}$, Mauro P. Soares ${ }^{2,3}$, Paulo M. Bandarra², Danilo C. \\ Gomes $^{2}$, Marcele B. Bandinelli², Claudio E.F. Cruz ${ }^{2}$ e David Driemeier ${ }^{2 \star}$
}

\begin{abstract}
Pavarini S.P., Soares M.P., Bandarra P.M., Gomes D.C., Bandinelli M.B., Cruz C.E.F. \& Driemeier D. 2011. [Sudden death in cattle due to the consumption of Amorimia exotropica (Malpighiaceae) in Rio Grande do Sul, Brazil.] Mortes súbitas em bovinos causadas por Amorimia exotropica (Malpighiaceae) no Rio Grande do Sul. Pesquisa Veterinária Brasileira 31(4):291-296. Setor de Patologia Veterinária, Faculdade de Veterinária, Universidade Federal do Rio Grande do Sul, Av. Bento Gonçalves 9090, Porto Alegre, RS 91540-000, Brazil. E-mail: davetpat@ufrgs.br

Cases of sudden death in cattle were associated with the consumption of Amorimia (Mascagnia) exotropica and occurred in six ranches located in the mountainous region of Rio Grande do Sul and the metropolitan region of Porto Alegre, Brazil. Affected cattle were found dead with no history of previous clinical signs, or showed muscular tremors, falls, paddling, opistotonus, panting, and lateral recumbence after being induced to move, few minutes before death. Most cases were recorded between May and August. Nine cattle were necropsied and main gross findings were oral mucosae slightly cyanotic (3/9), mild to intermediate hydropericardium (3/9), epicardial petechiae and ecchymoses (5/9), clot within the left ventricle (4/9), lung edema (5/9), apart of abomasal and small intestinal reddened mucosa (6/9). Histologically, there was myocardial coagulation necrosis (9/9), which was characterized by cellular retraction, enhanced cytoplasmic eosinophilia, lack of cytoplasmic striations, intracytoplasmic vacuoles, nuclear piknosis, intranuclear vacuoles, chromatin marginalization and occasional nuclear karyorrhexis and karyolysis. There also were interstitial edema (3/9) and interstitial inflammatory infiltrate (mainly mononuclear) (7/9) in the heart, apart of multifocal vacuolar-hydropic degeneration in the epithelial cells of the distal convoluted tubules associated with pyknotic and eccentric nuclei in the kidneys of three cattle.
\end{abstract}

INDEX TERMS: Poisonous plants, Amorimia exotropica, Mascagnia exotropica, Malpighiaceae, plant poisoning, sudden death, cattle.

RESUMO.- Descrevem-se casos de morte súbita em bovinos associados com a ingestão de Amorimia (Mascagnia) exotropica em seis propriedades rurais localizadas na região metropolitana de Porto Alegre e na serra gaúcha. Os bovinos intoxicados foram encontrados mortos sem história de sinais clínicos prévios, ou apresentaram tremores musculares, quedas bruscas, movimentos de pedala-

\footnotetext{
${ }^{1}$ Recebido em 6 de novembro de 2010.

Aceito para publicação em 11 de novembro de 2010

Parte da tese de Doutorado do primeiro autor.

2 Setor de Patologia Veterinária, Faculdade de Veterinária, Universidade Federal do Rio Grande do Sul (UFRGS), Av. Bento Gonçalves 9090, Porto Alegre, RS 91540-000, Brasil. *Autor para correspondência: davetpat@ufrgs.br

${ }^{3}$ Laboratório Regional de Diagnóstico, Faculdade de Veterinária, Universidade Federal de Pelotas (UFPel), Campus Universitário $s / n$, Pelotas, RS 96010-900, Brasil.
}

gem, opistótono, respiração ofegante e decúbito lateral, quando induzidos ao movimento poucos minutos antes da morte. Registrou-se maior número de casos entre os meses de maio e agosto. Nove bovinos foram necropsiados e os principais achados macroscópicos observados foram mucosa oral levemente cianótica (3/9), hidropericárdio leve a moderado (3/9), petéquias e equimoses no epicárdio (5/ 9), coágulo no interior do ventrículo esquerdo (4/9), edema pulmonar (5/9) e mucosas vermelhas no abomaso e no intestino delgado (6/9). Histologicamente havia necrose de coagulação no miocárdio (9/9) caracterizada por retração celular, aumento da eosinofilia do citoplasma com perda das estriações, vacúolos intracitoplasmáticos, núcleos em picnose, vacúolos intranucleares com marginalização da cromatina e ocasionais núcleos em cariorrexia e cariólise. No coração, edema intersticial (3/9) e infiltrado inflamatório intersticial predominantemente mononuclear (7/9) tam- 
bém foram observados. Nos rins de três bovinos havia degeneração hidrópico-vacuolar multifocal das células epiteliais dos túbulos contorcidos distais associada com núcleos picnóticos deslocados para periferia da célula.

TERMOS DE INDEXAÇÃO: Plantas tóxicas, Amorimia exotropica, Mascagnia exotropica, Malpighiaceae, intoxicação por planta, morte súbita, bovinos.

\section{INTRODUÇÃO}

Atualmente no Brasil, doze plantas tóxicas são causas reconhecidas de mortes súbitas em animais de fazenda. Essas plantas, as quais são responsáveis por mais da metade das mortes em bovinos intoxicados naturalmente por plantas no país, incluem espécies contidas nas famílias Rubiaceae (Palicourea marcgravii, Palicourea aeneofusca, Palicourea juruana, Palicourea grandiflora), Bignoniaceae (Pseudocalymma elegans, Arrabidaea bilabiata, Arrabidaea japurensis) e Malpighiaceae (Mascagnia rigida, Mascagnia elegans, Mascagnia pubiflora, Mascagnia aff. rigida, Mascagnia exotropica) (Tokarnia et al. 2000, Riet-Correa \& Mendes 2007). Recentemente, Mascagnia exotropica foi reclassificada como Amorimia exotropica (Anderson 2006) que é um semi-arbusto com ramos em forma de lianas (cipós) (Fig.1-3). A planta já foi identificada nos estados do Paraná, Santa Catarina e Rio Grande do Sul, bem como na
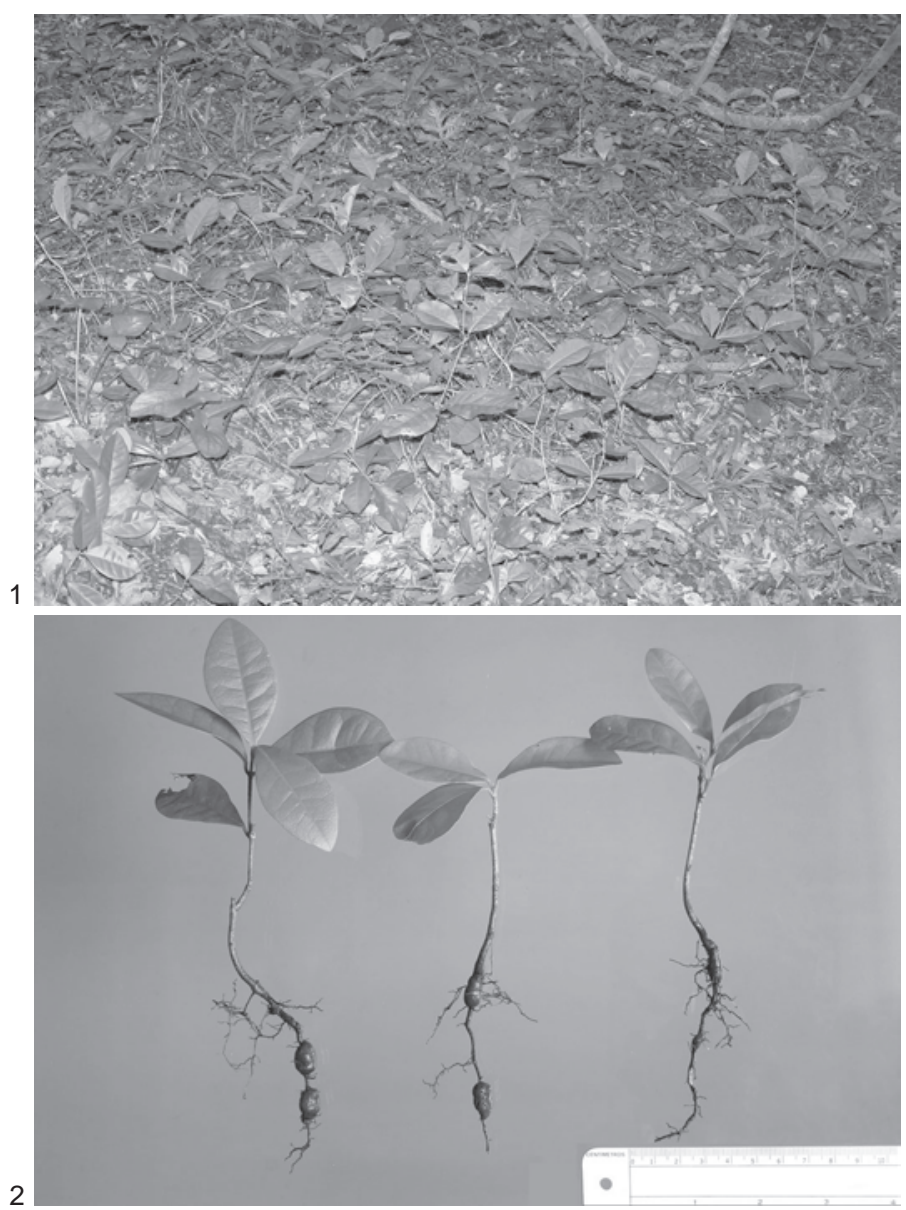

província de Missiones, Argentina (Anderson 2006). Inicialmente, Mascagnia sp. foi descrita como tóxica e responsabilizada por casos de morte súbita em bovinos em Santa Catarina (municípios de Tubarão, Imaruí, Jaguaruna, São Ludgero, Braço do Norte, Pedras Grandes, Urussanga, Nova Veneza e Jacinto Machado), onde, alguns proprietários relataram perdas, por morte repentina, de até $40 \%$ dos seus rebanhos, em apenas um ano. A toxicidade da planta para bovinos foi comprovada pela reprodução experimental da doença na espécie, através da administração oral da planta em doses únicas de $7,5-10 \mathrm{~g} / \mathrm{kg}$. No mesmo estudo, doses únicas de $5 \mathrm{~g} / \mathrm{kg}$ das folhas frescas de $A$. exotropica causaram intoxicação não-letal (Gava et al. 1998). A maioria dos bovinos intoxicados é encontrada morta, sem qualquer registro de alterações clínicas prévias. Alguns bovinos morrem alguns minutos depois de movimentados; tempo durante o qual podem apresentar taquicardia, cansaço, ingurgitamento da veia jugular, tremores musculares, contrações bruscas, decúbito esternal que evolui para lateral, além de quedas súbitas (Gava et al. 1998). As alterações observadas durante a necropsia são escassas e incluem avermeIhamento da mucosa do intestino delgado e edema da parede da vesícula biliar. A principal alteração histológica associada com a doença é degeneração hidrópico-vacuolar do epitélio tubular renal; entretanto, essa alteração não é observada em todos os bovinos intoxicados (Gava et al. 1998). Esse trabalho relata a ocorrência de "morte súbita" em bovinos associada com a ingestão de Amorimia exotropica em propriedades localizadas na região metropolitana de Porto Alegre e na serra gaúcha, bem como caracteriza os achados epidemiológicos, clínicos e patológicos associados com a intoxicação.

\section{MATERIAL E MÉTODOS}

Efetuou-se o levantamento dos casos de intoxicação por Amorimia exotropica em bovinos diagnosticados pelo Setor de

Fig.1. Brotação de Amorimia exotropica (fam. Malpighiaceae) em ambiente sombreado.

Fig. 2. Aspecto da raiz dos brotos de Amorimia exotropica.

Fig.3. Ramos de Amorimia exotropica sobre uma árvore, com seus frutos alados (no detalhe).

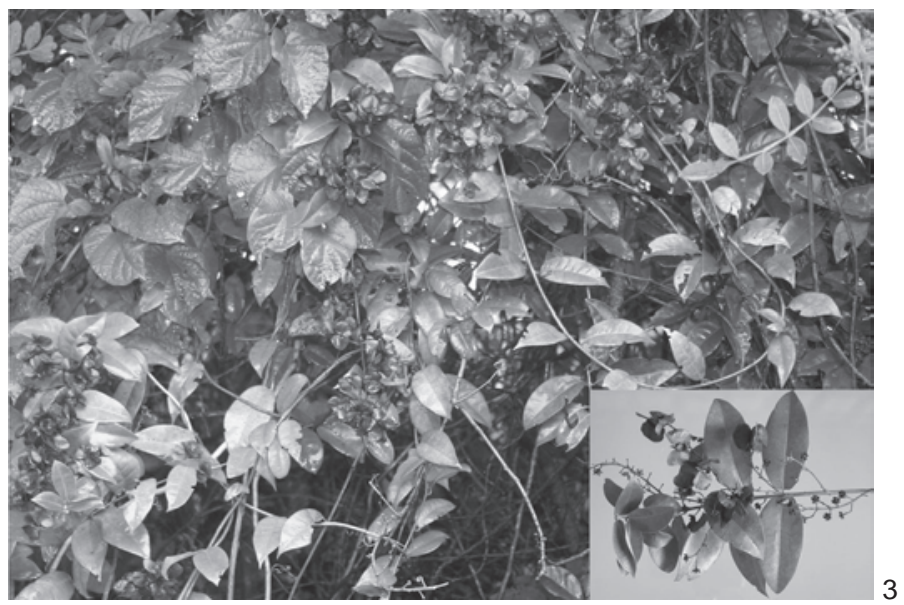


Patologia Veterinária (SPV) da Universidade Federal do Rio Grande Sul (UFRGS) entre 1999 e 2010. As necropsias foram realizadas nas propriedades e os dados epidemiológicos e clínicos foram obtidos junto aos veterinários, proprietários e funcionários dos estabelecimentos. Durante as visitas às propriedades, realizaram-se buscas para a detecção de plantas tóxicas, entre as quais, $A$. exotropica. Foram realizadas nove necropsias e fragmentos de diversos órgãos foram coletados e fixados em solução de formalina $10 \%$, processados de forma rotineira para histologia, incluídos em parafina, cortados a 3$5 \mu$ de espessura e corados pela hematoxilina e eosina (HE).

\section{RESULTADOS}

No período do estudo, acompanharam-se seis propriedades com problemas de morte súbita em bovinos (Propriedades A-F). Nas inspeções a procura de plantas tóxicas Amorimia exotropica foi encontrada em todos os surtos. $\mathrm{Na}$ Propriedade A, localizada em Porto Alegre/RS, em maio de 1999, morreram quatro de um rebanho com 800 bovinos de corte que eram mantidos em piquetes com pastagem nativa e suplementados com sal mineral no cocho. Quinze bovinos invadiram e permaneceram durante cinco dias em uma área de mata com aguada, onde se identificou a presença de $A$. exotropica. Durante a movimentação desses bovinos para recolhimento em mangueira e redistribuição aos piquetes originais, um bovino (Bovino 1) apresentou tremores musculares intensos que precederam a morte, outro (Bovino 2) morreu subitamente durante a permanência nas mangueiras, outro morreu durante o caminho ao piquete e outro foi encontrado morto na mata. Os bovinos um e dois foram necropsiados.

Na Propriedade B, situada em Rolante/RS, durante os meses de maio a novembro de 2004, morreram 11 bovinos adultos de um total de 35 bovinos de corte. Os animais foram encontrados mortos no campo sem registro de sinais clínicos prévios, ou estavam aparentemente bem, mas quando movimentados, apresentavam tremores musculares generalizados, incoordenação motora, decúbito lateral e morte, em cursos de dois a cinco minutos. Esses bovinos tinham acesso a uma área de mata na encosta de um morro, onde havia severa infestação por $A$. exotropica. Nessa propriedade, um animal (Bovino 3) ficou para trás, durante a movimentação de rotina para as mangueiras, deitou, permaneceu em decúbito esternal e apresentou ingurgitamento das veias jugulares (Fig.4). Quando estimulado a levantar, apresentou tremores musculares intensos e, rapidamente caiu em decúbito lateral, apresentou movimentos de pedalagem e morte, em um curso de 3 minutos.

$\mathrm{Na}$ Propriedade C, localizada em Dois Irmãos/RS, havia um rebanho de 20 bovinos em um piquete de campo nativo com área de 1,5 hectares e pouca disponibilidade de pasto. Em junho de 2006, os bovinos ganharam acesso a um piquete novo, no qual havia uma capoeira, onde se observaram exemplares de $A$. exotropica com sinais de terem sido consumidos. Um mês após a entrada dos animais nesse novo piquete, dois "bois de canga" adultos morreram de forma súbita durante o trabalho. Trinta dias após, outro bovino (fêmea mestiça, sete anos, bovino 4)

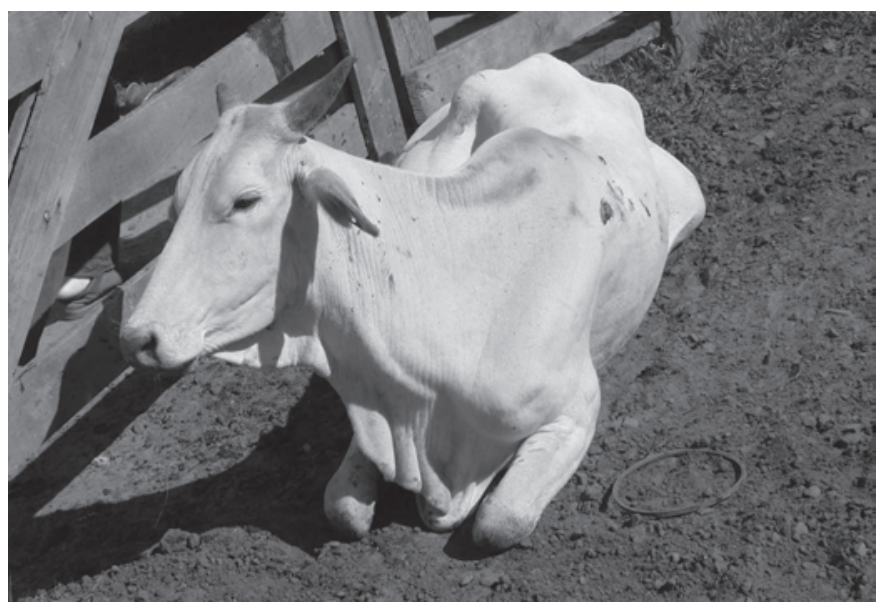

Fig.4. Bovino em decúbito external com a veia jugular ingurgitada, intoxicado pela ingestão de Amorimia exotropica no Estado do Rio Grande do Sul.

morreu subitamente sem qualquer alteração prévia registrada e foi necropsiado.

Na Propriedade D, situada em Estância Velha/RS, em outubro de 2007, morreram três novilhas holandesas de dois anos de idade que eram suplementadas no cocho e mantidas em um piquete com outras 23 novilhas e quatro vacas secas. Durante a transferência de campo, as noviIhas ficaram para trás do resto do rebanho. Quando o funcionário voltou para buscá-las, duas estavam mortas e outra, que estava em decúbito esternal, ao ser estimulada a levantar, relutou ao movimento, permaneceu deitada e, duas horas após, foi encontrada morta. Durante vistoria em uma área de mata em encosta de morro no campo onde os bovinos estavam, detectou-se $A$. exotropica. As três novilhas (Bovinos 5-7) foram necropsiadas.

As demais propriedades (E e F), localizadas em Novo Hamburgo, Lomba Grande, foram visitadas em agosto de 2010. Na Propriedade E, em um potreiro com 14 hectares de campo nativo, onde permaneciam 80 bovinos suplementados em cocho, havia registros de mortes súbitas sucessivas de bovinos há anos. Essas mortes eram associadas com transferências de campos, ou com movimentações de animais para manejo. Alguns caiam subitamente, apresentavam tremores, respiração ofegante e morriam em poucos minutos. No período entre julho de 2009 a agosto de 2010, foram registradas 17 dessas mortes em bovinos nesse campo, destas 11 ocorreram entre maio e agosto de 2010. Na parte mais alta (morro) do potreiro havia acesso a uma área de mata, onde foi identificada grande quantidade de brotos de $A$. exotropica. Nessa propriedade foi necropsiada uma vaca Angus de quatro anos (Bovino 8) que caiu abruptamente ao chegar nas mangueiras, apresentou tremores, ingurgitamento jugular e morte. A Propriedade F mantinha, apenas durante o inverno, 70 bovinos Angus que permaneciam em potreiro com pastagem de aveia e azevém e eram suplementados com silagem no cocho. Os bovinos eram repontados todos os dias, no período da tarde, para os cochos. No período entre 2009 e outubro de 2010, oito bovinos morre- 

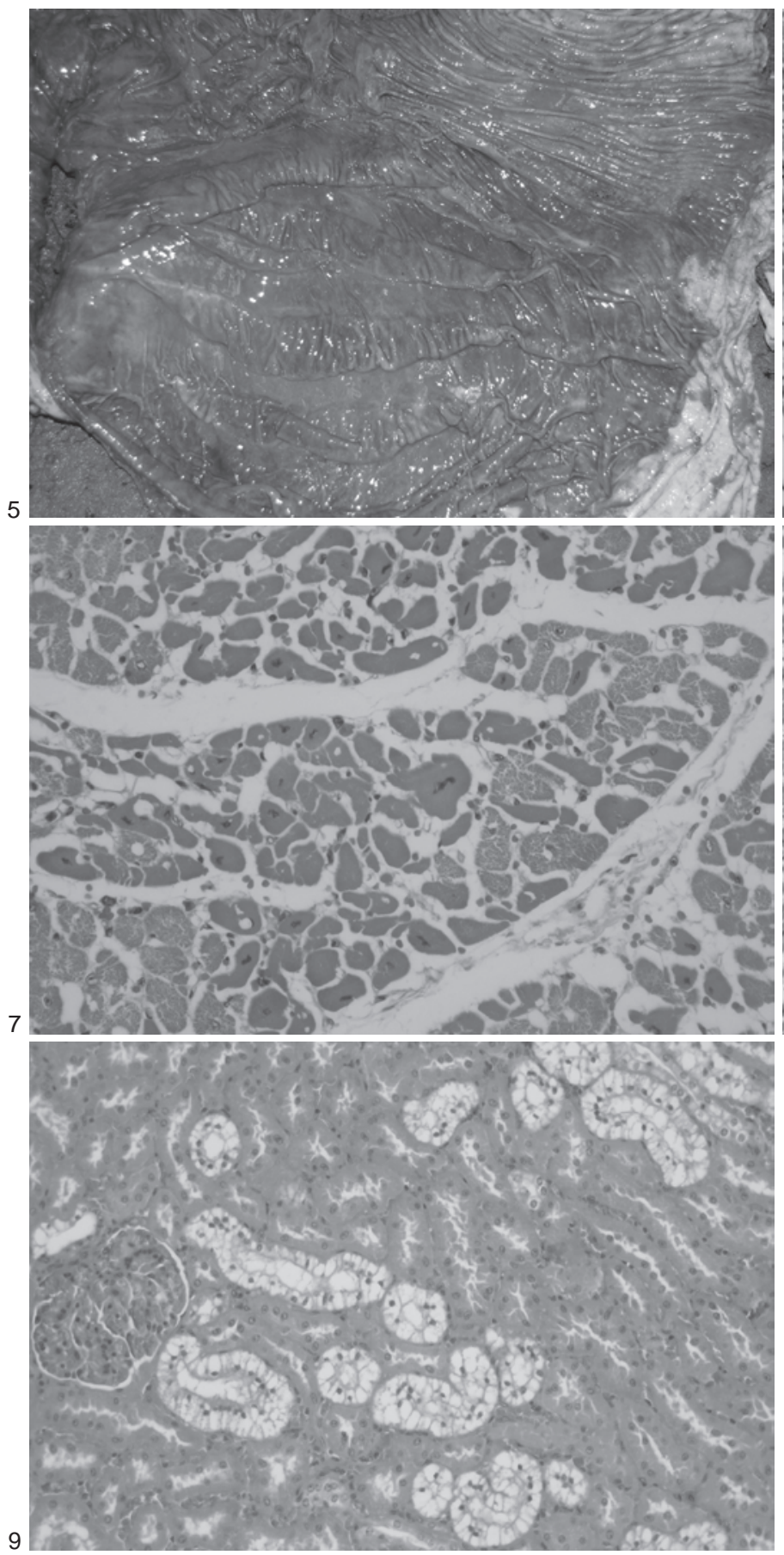

ram. Alguns foram encontrados mortos sem qualquer sinal prévio, outros morreram durante o trajeto entre cocho e pastagem, alguns caiam, apresentavam tremores, mugidos constantes, movimentos de pedalagem, opistótono, respiração ofegante e morriam rapidamente. Em uma área de capoeira no piquete dos bovinos, havia grande quantidade de $A$. exotropica. Um boi, 10 meses, Angus (Bovino 9), caiu subitamente quando era levado ao cocho, ficou para trás do lote e, três horas após, foi encontrado morto no mesmo lugar.

Os achados de necropsia dos nove bovinos foram: mucosa oral levemente cianótica (Bovinos 4, 8 e 9), hidro-
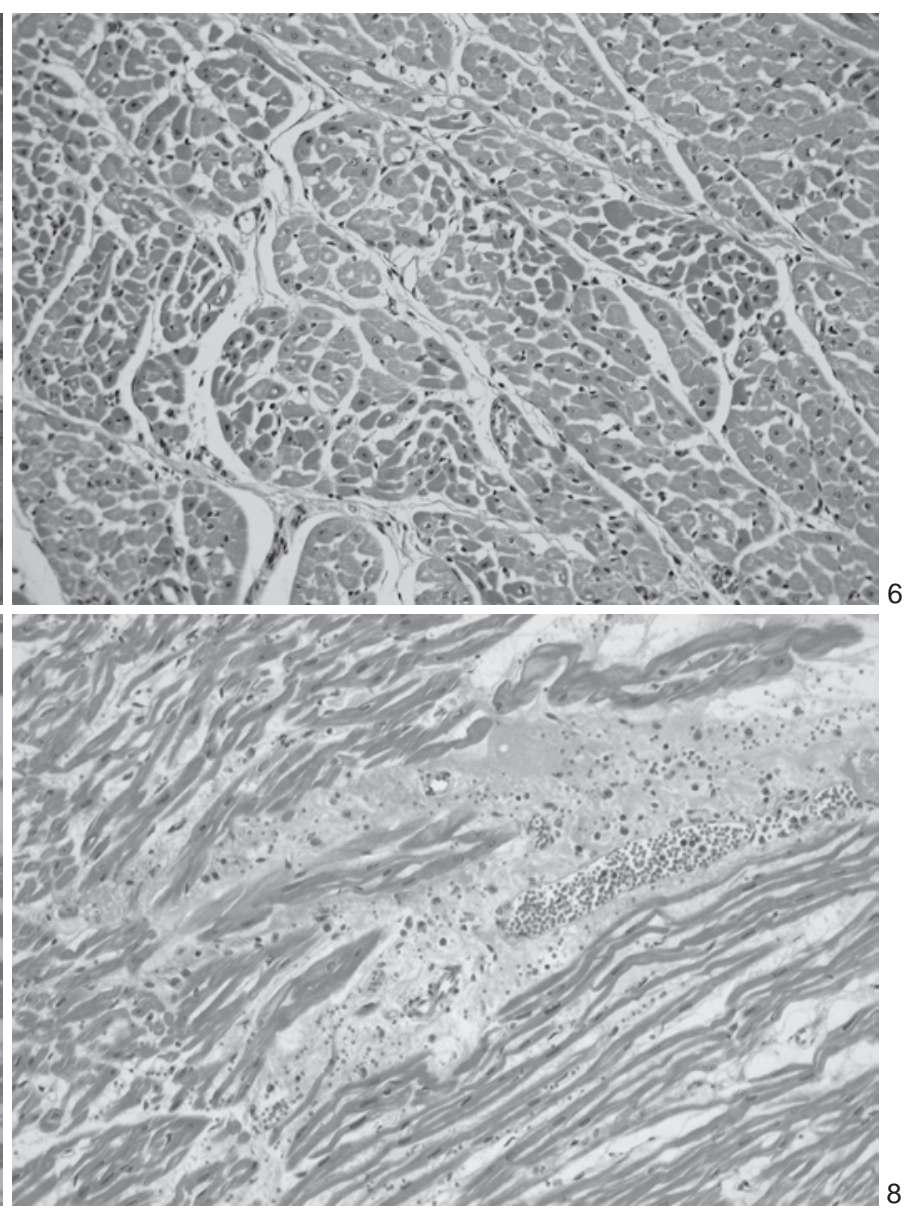

Fig.5. Abomaso com mucosa vermelha em bovino que morreu subitamente pela intoxicação por Amorimia exotropica.

Fig.6. Necrose de coagulação de fibras musculares cardíacas em bovino, após morte súbita pela intoxicação por Amorimia exotropica. HE, obj.10x.

Fig.7. Fibras cardíacas eosinofílicas com retração celular, picnose nuclear e com vaculos intra nucleares em bovino, após morte súbita por Amorimia exotropica. HE, obj.40x.

Fig.8. Edema intersticial e hemorragia discreta no coração em bovino, após morte súbita por Amorimia exotropica. HE, obj.40x.

Fig.9. Parênquima renal com degeneração hidropico-vacular das células epiteliais dos tubulos contorcidos distais em bovino, após morte súbita por Amorimia exotropica. HE, obj.10x.

pericárdio leve a moderado (Bovinos 3, 8 e 9), petéquias e equimoses epicárdicas (Bovinos 4-8), coagulo cruórico no interior do ventrículo esquerdo (Bovino 5-7 e 9), edema pulmonar (Bovino 1, 3, 5-7), mucosas do abomaso e do intestino delgado vermelhas (Bovinos 4-9) (Fig.5), além de leve acentuação do padrão lobular hepático (Bovino 4).

Ao exame histopatológico, no miocárdio dos nove bovinos necropsiados, observou-se necrose coagulativa em grupos de fibras musculares ou células individuais (Fig.6). A alteração era caracterizada por retração celular, aumento da eosinofilia do citoplasma com perda das estriações, 
vacúolos intracitoplasmáticos, núcleos picnóticos, vacúolos intranucleares com marginalização da cromatina e ocasionais núcleos em cariorrexia e cariólise (Fig.7). No coração, também havia edema intersticial com neutrófilos e deposição de fibrina (Bovinos 5-7) (Fig.8), focos de hemorragia entre as fibras musculares (Bovinos 5-7 e 9) e infiltrado inflamatório intersticial multifocal leve composto por macrófagos e linfócitos e, em menor escala, neutrófilos (Bovinos 3-9). As alterações histológicas observadas nos rins incluíram degeneração hidrópico-vacuolar multifocal das células epiteliais dos túbulos contorcidos distais com núcleos picnóticos e deslocados para periferia da célula (Bovinos 1, 3 e 6) (Fig.9), tumefação do epitélio dos túbulos renais (Bovinos 4, 7-9) e infiltrado inflamatório linfoplasmocitário intersticial multifocal leve no córtex renal (Bovino 1-4, 7 e 8). No abomaso e no intestino delgado, havia congestão de submucosa e mucosa (Bovinos 3-9). No parênquima hepático também foram observados, congestão (Bovinos 1-3, 5, 7 e 9), necrose paracentral (Bovinos 1 e 6) e tumefação hepatocelular, predominantemente, centro lobular (Bovinos 3, 4 e 9).

\section{DISCUSSÃO E CONCLUSÕES}

O diagnóstico de intoxicação por Amorimia exotropica nos bovinos desse estudo se baseou nos achados epidemiológicos, clínicos e patológicos associados com a presença de $A$. exotropica nas áreas de acesso dos bovinos. Em todas as propriedades, $A$. exotropica foi encontrada em ambiente sombreado, no interior e beira de matas e capões, principalmente, em encostas de morros. Os ramos de $A$. exotropica, em sua maioria, se estendiam sobre as copas das árvores, fora do alcance do gado que tinha acesso apenas aos brotos das plantas, os quais, muitas vezes, predominavam entre a vegetação rasteira no interior das matas.

As intoxicações ocorreram durante todo ano; entretanto, houve maior concentração de casos entre os meses de maio e agosto, o que pode estar relacionado à carência de alimento comum nesta época do ano no Sul do Brasil. Desta forma, os bovinos podem invadir áreas de matas ou capões à procura de alimento. Outra hipótese se refere à procura de abrigo das chuvas e ventos frios que também se concentram nessa época, no Rio Grande do Sul. Os bovinos intoxicados eram encontrados mortos sem registros de sinais clínicos prévios, ou morriam, quando eram movimentados. O estímulo do exercício físico intensificou a manifestação clínica da doença, fato também observado em bovinos intoxicados por $A$. exotropica em Santa Catarina, como também por outras plantas que causam morte súbita no Brasil (Gava et al. 1998, Tokarnia et al. 2000). Esse efeito provavelmente é causado por interferência no mecanismo energético celular, pois o esforço físico promove um aumento na necessidade energética.

Achados clínico-patológicos tais como ingurgitamento jugular, hidropericárdio, coágulos no interior do ventrículo esquerdo, edema pulmonar, congestão hepática e do trato gastrintestinal são típicos de insuficiência cardíaca aguda. As plantas que causam morte súbita em bovinos no Brasil interferem com o funcionamento cardíaco, de forma que os animais morrem de insuficiência cardíaca aguda (Tokarnia et al. 2000). A principal alteração histopatológica observada em bovinos intoxicados pelas plantas que causam morte súbita é degeneração hidrópico-vacuolar das células epiteliais dos túbulos contorcidos distais dos rins e é associada à cariopicnose (Tokarnia et al. 2000). Entretanto, essa alteração pode não ser visualizada em todos os animais intoxicados. No presente estudo, essa alteração foi observada em três dos nove bovinos necropsiados. Gava e colaboradores (1998) observaram essa alteração em três de cinco bovinos intoxicados por $A$. exotropica. Leve infiltrado inflamatório linfoplasmocitário intersticial multifocal no rim foi identificado em seis bovinos. Tal lesão é denominada nefrite segmentar, alteração comumente observada em bovinos, mas que não deve ser correlacionada com a intoxicação (Helayel et al. 2009). A lesão histológica observada com maior frequência nos bovinos ( $100 \%$ dos casos) desse estudo foi necrose de coagulação de grupos ou de fibras musculares isoladas no coração. Lesões similares foram descritas em bovinos intoxicados por outra planta que causa morte súbita no Brasil, Pseudocalymma elegans (Helayel et al. 2009). Gava et al. (1998) observaram somente aumento de eosinofilia das fibras cardíacas de bovinos intoxicados com $A$. exotropica.

O principio tóxico de $A$. exotropica é desconhecido; entretanto os achados clínicos e patológicos nos bovinos intoxicados são similares aos observados em bovinos afetados por plantas como Palicourea marcgravii, Arrabidaea bilabiata e Mascagnia rigida, nas quais já se identificou, cromatograficamente, a presença de monofluoracetato (Krebs et al. 1994, Cunha et al. 2006). Adicionalmente, bovinos que receberam monofluoracetato de sódio por via oral apresentaram quadro clínico-patológico indistinguível do observado em bovinos que ingeriram plantas que causam morte súbita no Brasil (Nogueira et al. 2010). Em várias propriedades, os criadores e proprietários associaram as mortes súbitas dos bovinos à ingestão de um cipó lactescente denominado por eles de "timbó" e identificado como Oxypetalum banksii. Tal hipótese pode ser descartada, pois essa planta não é tóxica para bovinos, conforme demonstrado em experimentos prévios (Tokarnia et al. 1967).

Os diagnósticos diferenciais devem incluir doenças e intoxicações de evolução rápida que causem poucos sinais clínicos e ocorram nessa região, tais como carbúnculo hemático (Schild et al. 2006), fulguração (Watanabe et al. 2010), intoxicações por Nerium oleander (Pedroso et al. 2009), timpanismo agudo por excesso de leguminosas (Dalto et al. 2009) e intoxicação por plantas que contêm ácido cianídrico (Riet-Correa \& Mendes 2007). Entretanto, em todas essas doenças e intoxicações, os bovinos afetados apresentam lesões características, além de achados epidemiológicos distintos.

A. exotropica está presente na região metropolitana de Porto Alegre e na serra gaúcha e seu envolvimento com "mortes súbitas" em bovinos deve ser incluído na lista dos diagnósticos diferenciais e na adoção de medidas preven- 
tivas. A distribuição geográfica das diferentes espécies de plantas tóxicas é um dado de extrema importância para os diagnósticos definitivos. As perdas econômicas associadas com a intoxicação por $A$. exotropica nessas regiões são desconhecidas; entretanto, é possível que sejam consideráveis, pois há muitos relatos de mortes súbitas de bovinos após movimentações e de produtores que desistiram da criação de bovinos devido às constantes perdas. $\mathrm{A}$ importância da doença é muitas vezes subestimada devido ao desconhecimento da planta pelos produtores e técnicos dessas regiões. Estudos adicionais são necessários para avaliar o real impacto da intoxicação e promover o reconhecimento de Amorimia exotropica nessas regiões.

Agradecimentos.- Ao Conselho Nacional de Desenvolvimento Científico e Tecnológico (CNPq) pelo auxílio financeiro deste trabalho (Proc.478842/2009-0). O material usado de arquivo teve a participação de diversos membros do Setor de Patologia Veterinária da UFRGS, em especial agradecemos aos Colegas Andre Mendes Ribeiro Correa, Edson Moleta Colodel, Alexandre Paulino Loretti e Anderson Seitz.

\section{REFERÊNCIAS}

Anderson W.R. 2006. Eight Segregates from the neotropical genus Mascagnia (Malpighiaceae). Novon 16(2):168-204.

Cunha L.C., Gorniak S.L., Haraguchi M., Riet-Correa F., Xavier F.G. \& Florio J.C. 2006 Palicourea marcgravii e Mascagnia rigida: um estudo por cromatografia em camada delgada (CCD). II Simpósio de Pós-Graduação e XV Semana Científica Prof. Dr. Benjamin Eurico Malucelli, USP, São Paulo. (Resumo em CD-ROM)

Dalto A.G.C., Bandarra P.M., Pedroso P.M.O., Guagnini F.S., Leal J.S., Raymundo D.L. \& Driemeier D. 2009. Timpanismo espumoso em bovinos leiteiros em pastagem de Trifolium spp. (Leg. Caesalpinoideae). Pesq. Vet. Bras. 29:401-403.

Gava A., Cristani J., Branco J.V., Neves D.S., Mondadori A.J. \& Souza
R.S. 1998. Mortes súbitas em bovinos causadas pela ingestão de Mascagnia sp. (Malpighiaceae), no Estado de Santa Catarina. Pesq. Vet. Bras. 18:16-20.

Helayel M.A., França T.N., Seixas J.N., Nogueira V.A., Caldas S.A. \& Peixoto P.V. 2009 Morte súbita em bovinos causada pela ingestão de Pseudocalymma elegans (Bignoniaceae) no município de Rio Bonito, RJ. Pesq. Vet. Bras. 29:498-508.

Krebs H.C., Kemmerling W. \& Habermehl G. 1994. Qualitative and quantitative determination of fluoroacetic acid in Arrabidaea bilabiata and Palicourea marcgravii by F-NMR spectroscopy. Toxicon 32:909913.

Nogueira V.A., França T.N., Peixoto T.C., Caldas S.A., Armién A.G. \& Peixoto P.V. 2010. Intoxicação experimental por monofluoroacetato de sódio em bovinos: aspectos clínicos e patológicos. Pesq. Vet. Bras. 30:533-540.

Pedroso P.M.O., Bandarra P.M., Bezerra Junior P.S., Raymundo D.L., Borba M.R., Leal J.S. \& Driemeier D. 2009. Intoxicação natural e experimental por Nerium oleander (Apocynaceae) em bovinos no Rio Grande do Sul. Pesq. Vet. Bras. 29:404-408.

Riet-Correa F. \& Mendez M.C. 2007. Intoxicação por plantas e micotoxinas, p.99-221. In: Riet-Correa F., Schild A.L., Lemos R.A.A. \& Borges J.R.J. (Eds), Doenças de Ruminantes e Eqüídeos.Vol.2. 3 ${ }^{\text {a }}$ ed. Pallotti, Santa Maria, RS. 694p.

Schild A.L., Sallis E.S.V., Soares M.P., Ladeira S.R.L., Schramm R., Priebe A.P., Almeida M.B. \& Riet-Correa F. 2006. Anthrax in cattle in southern Brazil, 1978-2006. Pesq. Vet. Bras. 26:243-248.

Tokarnia C.H., Canella C.F.C \& Döbereiner J. 1967. Experimentos com plantas suspeitas de serem tóxicas realizados em bovinos no Estado do Rio de Janeiro, que resultaram negativos ou em perturbações leves passageiras. Pesq. Agropec. Bras. 2:343-351.

Tokarnia C.H., Döbereiner J. \& Peixoto P.V. 2000. Plantas Tóxicas do Brasil. Editora Helianthus, Rio de Janeiro.

Watanabe T.T.N., Ferreira H.H., Gomes D.C., Pedroso P.M.O., Oliveira L.G.S., Bandarra P.M., Antoniassi N.A.B. \& Driemeier D. 2010. Fulguração como causa de morte em bovinos no Estado do Rio Grande do Sul. Pesq. Vet. Bras. 30:243-245. 